\title{
Study of Temporal Analysis on Earthquake Data and Statistical Seismology of Nepal
}

\author{
Noora Shrestha \\ Assistant Professor \\ Department of Mathematics and Statistics, Padma Kanya Multiple Campus, \\ Tribhuvan Universtiy \\ Kathmandu \\ Nepal
}

\begin{abstract}
An earthquake is the greatest terrifying natural disaster that can do significant damages. A 7.8 magnitude earthquake struck Barpak, which is located about 81 kilometers northwest of Kathmandu killing thousands and affecting millions of citizens on 25th April 2015. This is the most powerful disaster to strike Nepal since an earthquake in 1934. The aim of this paper is to study temporal analysis on earthquake data of Nepal and to provide some new analytical insights on the importance of statistical seismology. The data of aftershock occurrence followed by the most catastrophic natural disaster were studied using earthquake catalogue produced by the National seismological center Nepal and the United States geological survey. The catalog covers the time span from 1994 to 2015 and includes about 821 earthquakes having magnitude (ML) four or greater. Descriptive statistics are used to describe the basic features of the earthquake data for 22 years using Excel. The frequency-magnitude distribution of earthquakes has been analyzed in view of its application in seismic pattern study. The relationship between a number of events, time, magnitude, depth, latitude and longitude were studied and interpreted. People want to know the prediction of an earthquake but neither physical nor statistical models are sufficient for predictions and other analyses of a seismic pattern. The development of effective procedures and models for this issue may well require a fusion of statistical and physical ideas in ways, which differ radically from standard practice in either field.
\end{abstract}

Key Words: Nepal earthquake, Seismic pattern, Magnitude, Frequency-magnitude, Gutenberg-Richter.

\section{INTRODUCTION}

Earthquake activity varies spatially and temporally. Seismologists are trying to accurately describe the seismicity using statistical models, and based on these make forecasts of future seismicity. Plate tectonics explains a large portion of the worlds seismicity, since more than $90 \%$ of the seismicity occurs on plate margins. Seismologists develop a growing understanding about the spatial distribution of earthquakes; however, there are occasional sequences of earthquakes that occur in places where no seismicity has been observed previously $[1,2]$. Each earthquake is an individual thing with multiple characteristics. Earthquakes are typically followed by aftershock sequences. The identification of these sequences is usually a cumbersome problem, which requires an assumption on the spatial and temporal clustering of aftershocks [3]. On 25 ${ }^{\text {th }}$ April 2015, a 7.8 magnitude earthquake called Gorkha earthquake struck in the Barbak located about 81 kilometers northwest of the capital city Kathmandu killing thousands and affecting millions of citizens. This is the most powerful disaster to strike Nepal since an earthquake in 1934. The earthquake to date has affected over 50 districts of Nepal and caused an avalanche on Mount Everest, which killed approximately 20 people and injuring many [4].

All large earthquakes are followed by an increase of seismic activity known as 'aftershocks'. Aftershocks are defined as events of lesser magnitude following a larger main shock that are distributed over the fracture area of the main shock. Aftershock sequences of small earthquakes are less obvious because the aftershock productivity is weaker, but can be clearly observed when stacking many sequences [5]. It is thus natural to assume that each earthquake can trigger its own aftershock sequence, and that observed aftershock sequences result from the cascade of direct aftershocks and indirect aftershocks. Some problem concerns the 
relationship between the magnitude of the main shock, which initiated the aftershock sequence, and the magnitudes of the aftershocks. Aftershock sequences themselves have a complicated hierarchical structure in which each aftershock can produce its own aftershock sequence and so forth [3]. People want to realize the prediction of an earthquake but neither physical nor statistical models are sufficient for predictions and other analysis of a seismic pattern. A fundamental question in studies of aftershocks is: why do they occur? The simplified answer is that the main shock increases regional stresses resulting in the subsequent aftershocks. Another question concerning the aftershock is: what is the physics of the time delay associated with the occurrence of aftershocks? The stress transfer occurs at the time of the main shock, but aftershocks continue for months and years after the main shock [1,2]. The development of effective procedures and models for this issues may well require a fusion of statistical and physical ideas in ways, which differ radically from standard practice in either field [2].

Since seismic prediction is currently unattainable, one of the most important goals of seismologists is the determination of a seismic hazard. There are fourteen tectonic plates through out the world, out of which six are the major tectonic plates. The tectonic plate, under the Kathmandu city, shifted southwards $10 \mathrm{ft}$. over another plate along an ancient Himalayan fault line releasing a seismic shock wave with the strength of more than twenty thermonuclear weapons [6]. Scientists say the main reason for the occurrence of earthquakes in Nepal is obvious, as the country is located in a famous seismic zone; the MediterraneanHimalayan seismic belt [7].

The purpose of this paper is the study of earthquake catalog and temporal analysis of earthquake data of Nepal and to suggest the importance of statistical seismology for further studies with special reference to $25^{\text {th }}$ April 2015 Gorkha earthquake. To accomplish this, descriptive statistical measures are incorporated to study the properties of aftershock data. It is shown than how aftershock data are distributed and holds the characteristics of a shallow tremor. Finally, the discussion of different descriptive statistical values obtained from the study of aftershock data is presented.

\section{METHOD}

This paper aims to study the features of an earthquake and major aftershock occurrence after main shock on $25^{\text {th }}$ April 2015 in Nepal. The study is based on descriptive research design. The source catalogs for the input data of this study were the earthquake catalog produced by national seismological center, Nepal, and the United States geological survey earthquake data sheets. The data were analyzed with the help of Excel-pivot table. This study has analyzed the data available from the time period 1994 to 2015 December covering 22 years. The number of earthquake aftershock with magnitudes four and larger recorded by seismological centers were adopted as the target events. An earthquake data set used in seismicity or seismic studies must be homogenous and complete. All earthquake magnitudes should be in the same magnitude scale and a specific time period. A uniform magnitude scale, the local magnitude $\left(\mathrm{M}_{\mathrm{L}}\right)$ was applied throughout the catalog. The events that lack the magnitude and other information were excluded [8]. The percentage and mean value were calculated to portray the data. The data were explained using bar diagrams, histogram, and graphs.

\subsection{Gutenberg-Richter (G-R) Law}

The frequency-magnitude relation is a universal characteristic of earthquake activity and can be applied to global, regional, and local areas. The frequency-magnitude relation is sometimes called the Gutenberg-Richter relation, named after two famous seismologists who first described it [9]. It is well known that the G-R distribution or the frequency magnitude distribution (FMD) is described by a simple logarithmic linear equation of the form:

$$
\log _{10} \mathrm{~N}(\mathrm{~m})=\mathrm{a}-\mathrm{b} \mathrm{M} \text { or } \mathrm{N}=10^{(\mathrm{a}-\mathrm{b} M)}
$$

Where, $\mathrm{N}$ is the number of events having a magnitude $\geq \mathrm{M}$ and $\log \mathrm{N}$ is the logarithm of the number of earthquakes with magnitude of $\mathrm{M}_{\mathrm{L}}$.

Gutenberg-Richter law is used for seismic analysis and ' $a$ ' and ' $b$ ' values are determined and interpreted for few epicenters. In G-R relation, ' $a$ ' value is the intercept of the regression line and is characterized the seismic activity in the area related to the total number or annual rate of events. Theoretically $\mathrm{a}=\log \mathrm{N}$ at $\mathrm{M}=0$ and $\mathrm{a}=0$ when $\mathrm{N}=1$. The value of ' $\mathrm{a}$ ' usually ranges from 2 to 8 when dealing with the real data [10]. The ' $b$ ' value is the slope of the regression line that shows the relation between the number of large and small earthquake magnitudes and usually lies in the expected range of 0.5 to 1.5 [9].

The study was limited to use of electronically available data and literature. The study is focused on temporal analysis of earthquake and aftershock data but other areas like disaster management, psychological impact on people are not included in the study. This study also faced the limitation of the earthquake catalog where magnitude of the earthquake $\geq 4$ was included. The result and information of this study is preliminary and subject to change as more data become available.

\section{FINDINGS AND DISCUSSIONS}




\subsection{Diagrammatic Presentation}

The spatial distribution of an aftershock indicates that they are mainly crustal events; however, deeper sequences also take place. The analysis of the distribution of aftershocks in different places of Nepal with respect to time and magnitude leads to the statistical interpretation.

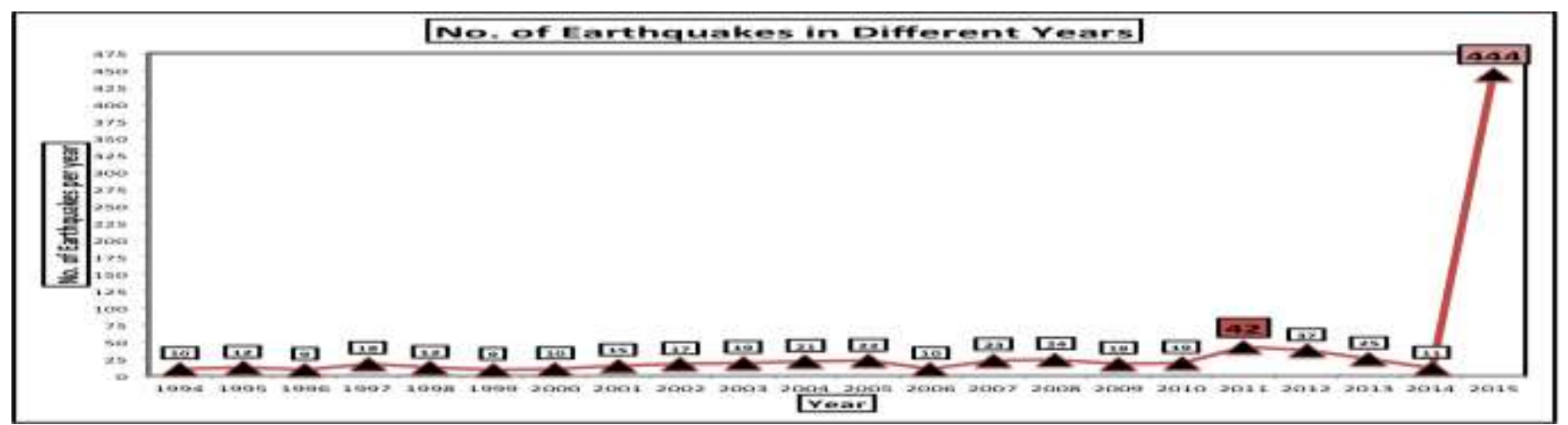

Figure 1: Number of Earthquakes in Different Years

Figure 1 demonstrates the number of earthquakes occurred during the year 1994 to 2015. In 1994, the number of earthquake occurrence was 10. The number of earthquakes ranged from 9 to 24 during 1995 to 2010. In 2015, the number of earthquakes > 4 magnitude were 444 including the main shock. The average number of earthquakes was found to be 18 per year from the year 1994 to 2014. Due to main shock on $25^{\text {th }}$ April, many earthquake aftershocks were recorded in 2015.

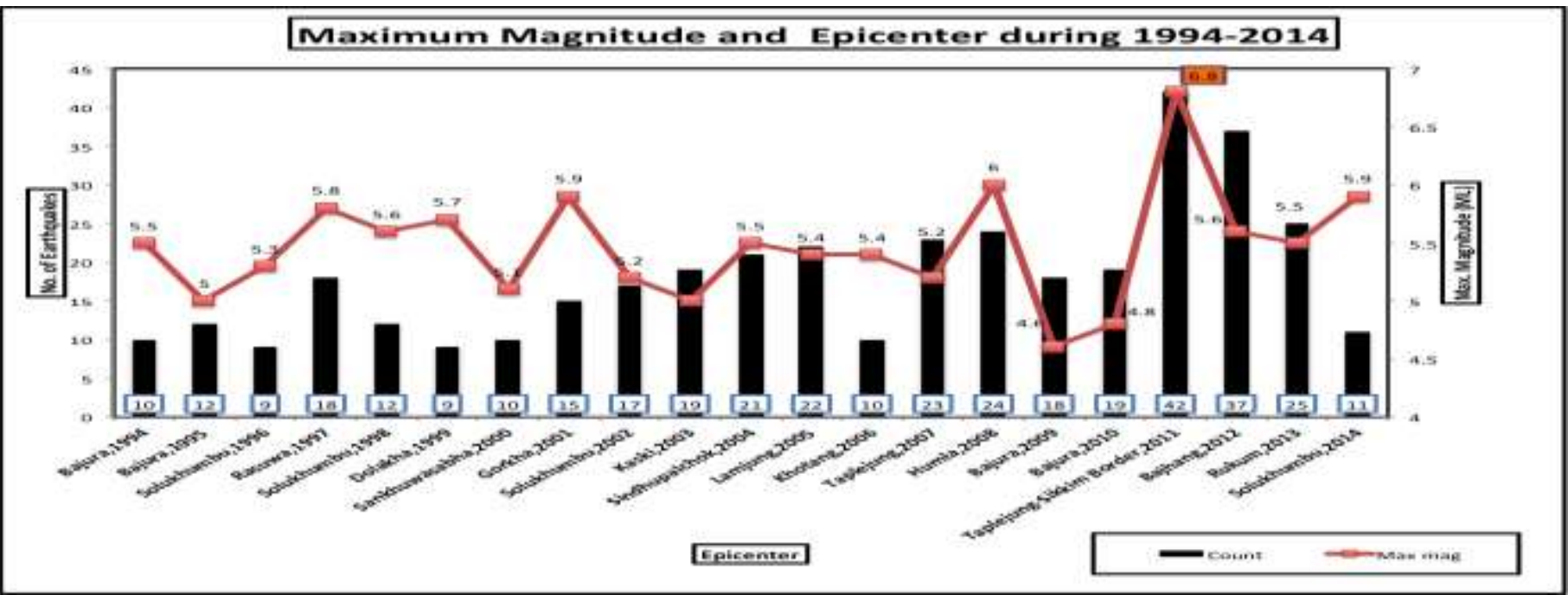

Figure 2: Maximum Magnitude and Epicenter during 1994-2014

Figure 2 illustrates the maximum magnitude of the earthquake occurrence and epicenter from 1994 to 2014 . During this time period, maximum magnitude was recorded as 6.8 magnitudes in the year 2011 near the boarder of Taplejung (Nepal) and Sikkim (India). Through this time period $52 \%$ of the earthquake was recorded in the western region of Kathmandu whereas $48 \%$ of the earthquake was recorded in eastern area of Kathmandu. 


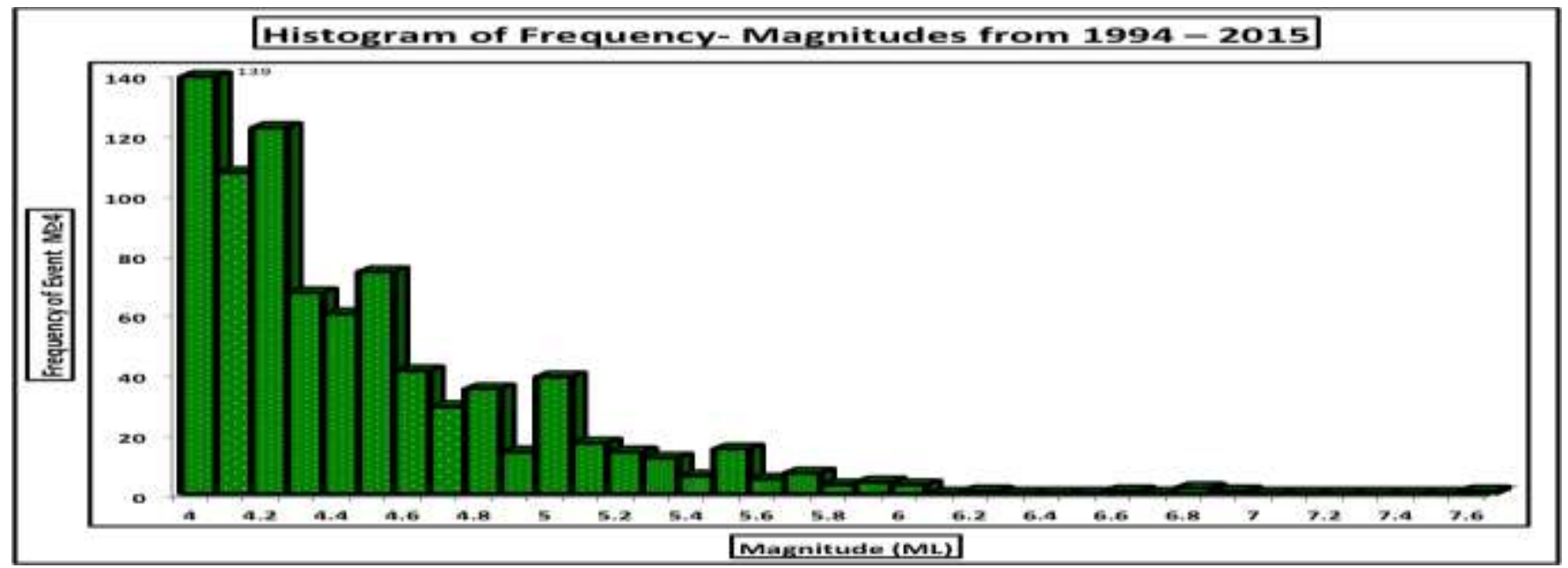

Figure 3: Histogram of Frequency-Magnitude from 1994-2015

Figure 3 displays histogram of frequency-magnitude from 1994-2015. There were 139 numbers of aftershocks with magnitude 4 and number was decreased when the magnitude increased to more than 6 . The analysis of an earthquake of magnitude greater than or equal to four exhibited that more number of earthquake aftershocks was recorded with low magnitudes whereas fortunately less number of aftershocks was recorded with high magnitude.

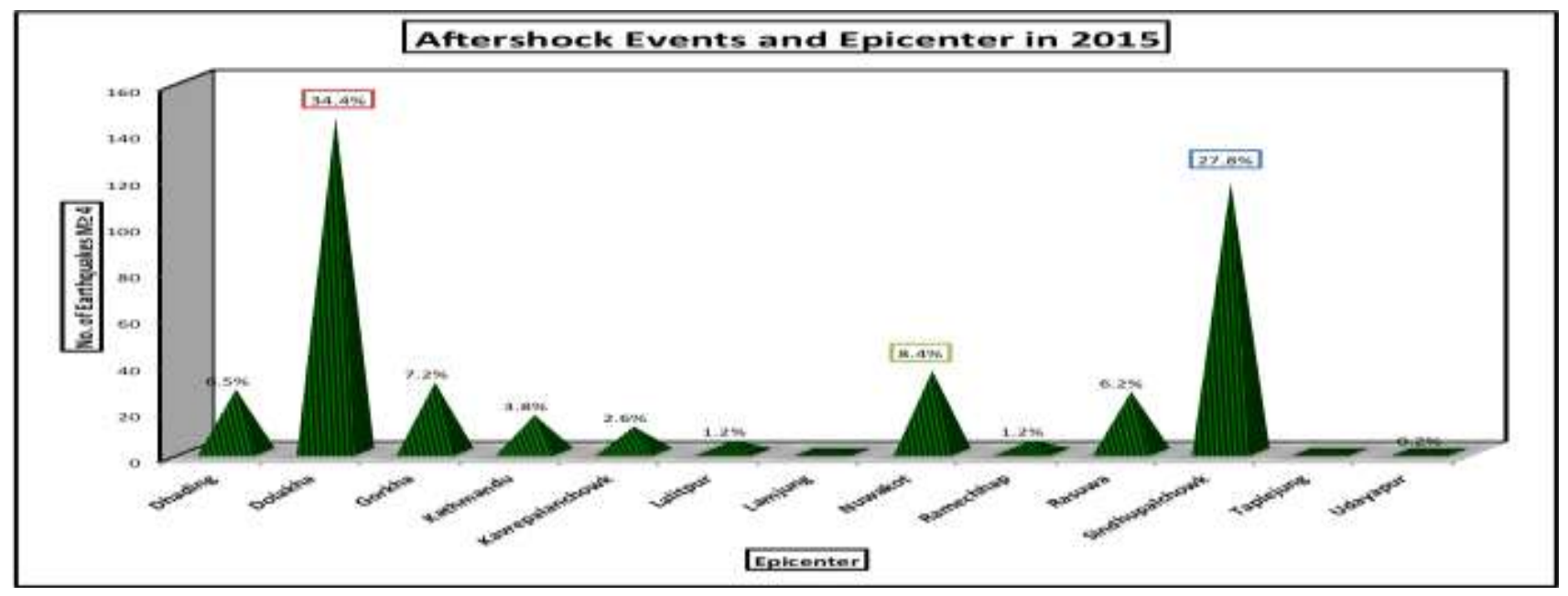

Figure 4: Aftershock Events and Epicenter in 2015

Figure 4 demonstrated aftershock events and epicenter in 2015. The analysis of number of events and epicenter shows that $34.4 \%$ of the aftershock was recorded in Dolakha district, $27.8 \%$ was in Sindhupalchowk district followed by $8.4 \%$ in Nuwakot district, 7.2\% in Gorkha, 6.5\% in Dhading district, 6.2\% in Rasuwa district, and rest in other districts of Nepal. Out of all districts of Nepal, about 10 districts were highly affected with main shock and continuous aftershock occurrence in the year 2015 .

\subsection{Gutenberg-Richter Law for Aftershock Data 2015}

The number of aftershocks satisfies Gutenberg-Richter frequency magnitude scaling just as all earthquakes do. The exponential pattern of relationship between frequency and magnitude is observed. The frequency magnitude distribution reflects fundamental properties of how earthquakes grow and stop [11]. The Gutenberg Richter parameters were calculates, by Least Square Method for aftershock data 2015, using the relation as

$$
\log 10 \mathrm{~N}(\mathrm{~m})=\mathrm{a}-\mathrm{b} \mathrm{M}=6.5-0.89 \mathrm{M} \text {. }
$$

This Gutenberg-Richter relation expresses the relationship between the magnitude and total number of earthquakes in any given region (Nepal) and time period of at least that magnitude $(\geq 4)$. The constant 'a' refers the productivity that relates to the number of aftershocks a sequence produces or a constant that depends on the region and time considered which indicated the overall degree of seismicity. Here, $a=6.5$ that lies in the range of value of ' $a$ ' which is assumed to be 2 to 8 dealing with real data. 
Here, the constant ' $b$ ' is slope parameter with 0.89 value which indicates this slope is slightly gentler i.e. more productive for the larger aftershock and lies in the expected range of 0.5 to 1.5 globally [10,11].

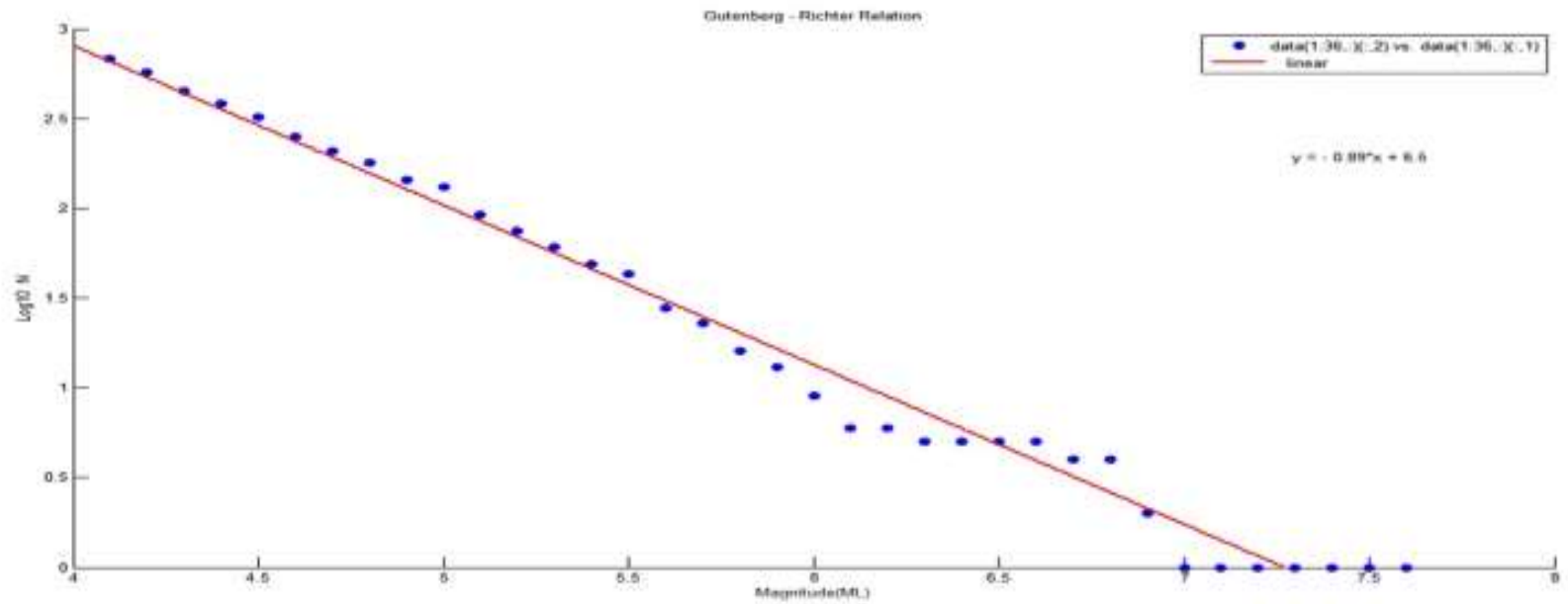

Figure 5: Gutenberg-Richter Relation

Figure 5 shows Gutenberg-Richter relation observed for the total number of earthquakes and magnitude under study. The logarithm of number of earthquakes $(\log \mathrm{N})$ is taken along the $\mathrm{Y}$-axis while magnitude is occupied along the $\mathrm{X}$-axis. Further, G-R relation is calculated for few districts to realize the productivity and slope parameters. The values of constants ' $a$ ' and ' $b$ ' were found to be 3.1 and 0.5 for 144 numbers of events in Dolakha district. Considering Sindhupalchowk district, the values were a = 4.8 and $b=0.86$ for 130 number of events of aftershocks. With 34 number of events in Nuwakot district, the values were computed as $a=2.7$ and $b=0.53$. The values of $b=0.92$ and $a=4.2$ were calculated for Kathmandu district with 16 number of events.

The b-value is an important parameter measured by seismologists because it tells us proportionately how many large and small events are there. A large value of ' $b$ ' indicates more similar sized events are likely whilst a small value of ' $b$ ' indicates a larger range of magnitudes $[12,13]$. In this case, Sindhupalchowk and Kathmandu districts had large value of ' $b$ ' that means these epicenters had experienced less deviation between maximum and minimum magnitudes of earthquakes whereas Dolakha and Nuwakot had more deviation of large and small earthquakes recorded in these epicenters. The calculated values of ' $a$ ' and ' $b$ ' for other epicenters did not give result in prescribed range mentioned by USGS $[14,15]$. The reason could be the calculation based on too small data set and least square method rather than maximum likelihood method. The maximum likelihood method is not used, as it requires large data set, which is not available in the earthquake catalog referred.

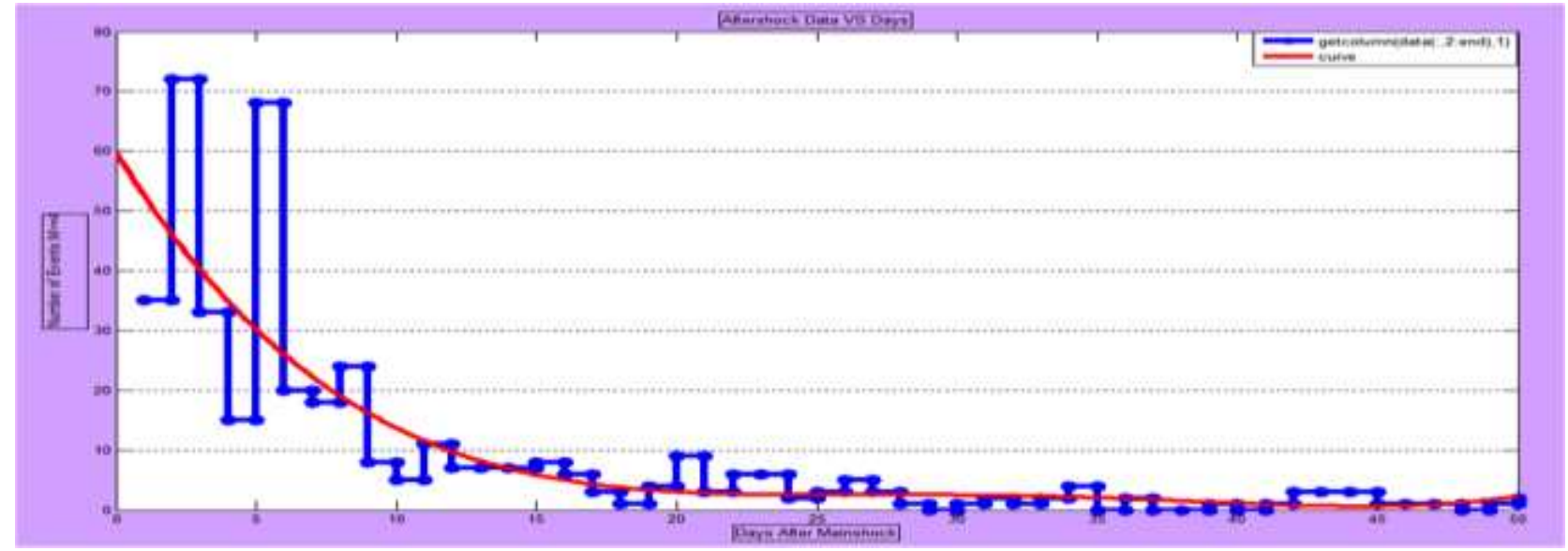

Figure 6: Exponential Decay Curve

Figure 6 illustrates the exponential decay curve of aftershock occurrence after $25^{\text {th }}$ April 2015. The aftershock data shows that the rate of aftershock occurrence decreases when time increases. The Omori's Law related to aftershocks decay rate states that the rate of aftershocks has been proportional to the inverse of time since the main shock [16]. There is exponential relationship between number of events of the aftershock and days after main shock. It shows when a day passes out the number of aftershocks decreases. 
The pattern of aftershocks also helps to confirm the size of area that slipped during the main shock. The data shows that most of the greater magnitude aftershock and more number of events was recorded in two districts of Nepal namely Sindhupalchowk and Dolakha. It means these two places had experienced more earthquakes that are destructive and still possibilities of getting more casualties.

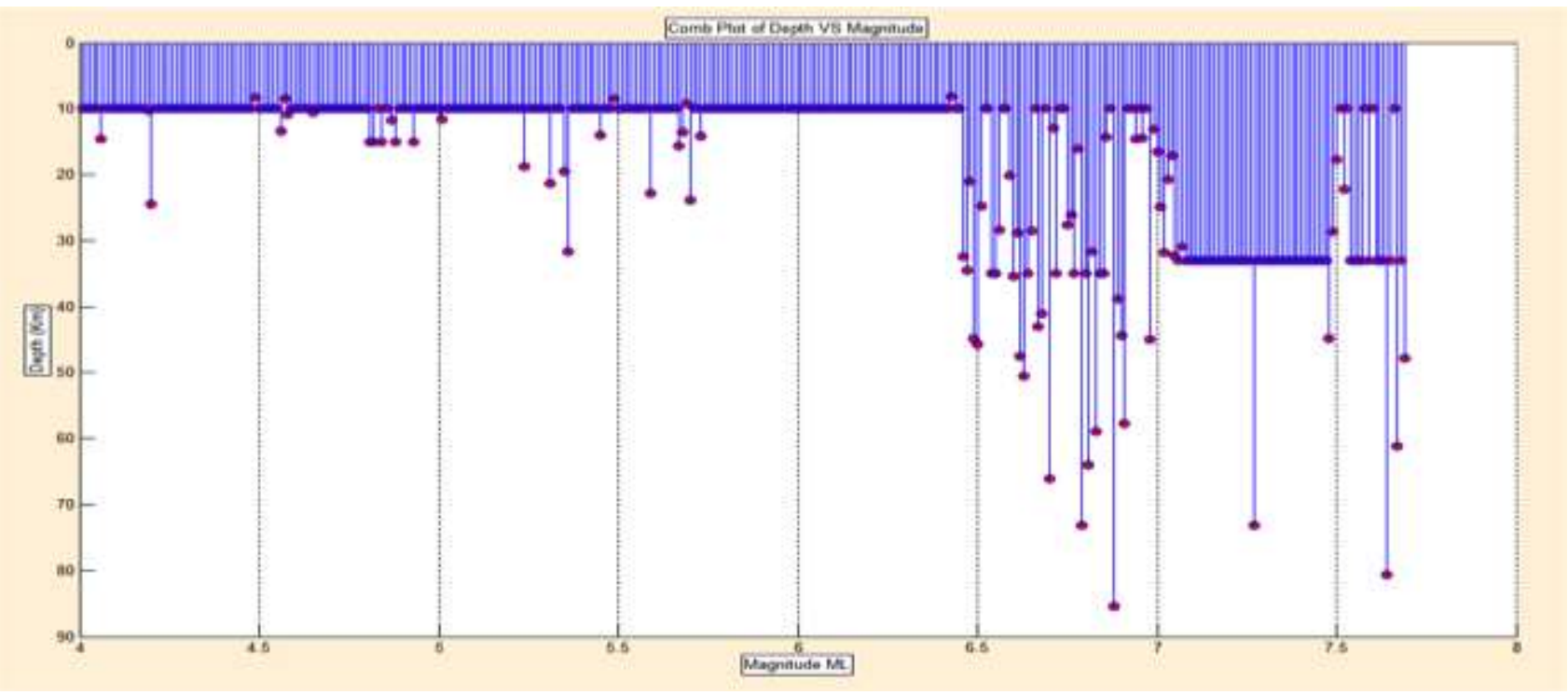

Figure 7: Comb Plot of Event-Depth Distribution: Shallow Tremor

Figure 7 displays the comb plot of depth along the $\mathrm{y}$-axis and magnitude of earthquake event along the $\mathrm{x}$-axis. The earthquake that occurs at the depth of 0 to 70 kilometers is considered as shallow tremor, $70-300 \mathrm{~km}$ as intermediate and $300-700 \mathrm{~km}$ is deliberated as deep [12]. The event of aftershock and depth distribution shows that the type of earthquake on $25^{\text {th }}$ April and other after main shock was the shallow tremor because most of the earthquake and its aftershocks were recorded at the depth of 10 kilometers in Nepal which is also considered as the most destructive type of earthquake.

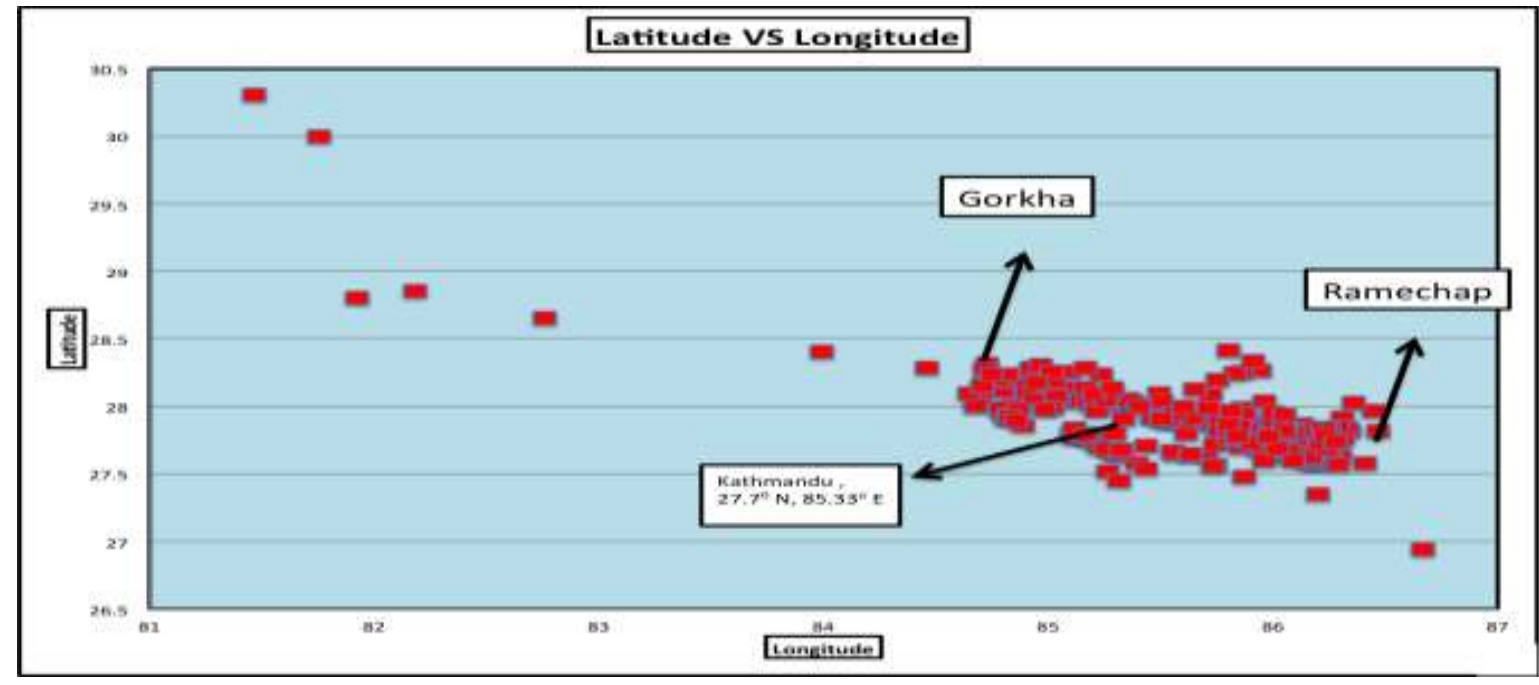

Figure 8: Scatter Diagram

The relationship between longitude and latitude shows that more concentration of aftershock data was found at 84.5 to 86.5 longitudes and 27.5 to 28.5 latitudes. It covers the area from Gorkha district where main shock occurred to Ramechap district towards the southeast direction and includes Kathmandu Valley. Seismologist believes that the fault line passes beneath the surface of this land. The expected location of the aftershocks will be in the zone of activity and at its perimeter with a few locations further away. Almost all aftershocks are occurring in a zone extending approximately $200 \mathrm{~km}$ away from the main shock epicenter with a few occurring up to $400 \mathrm{~km}$ to the east and southeast [4]. 


\section{CONCLUSION}

This study has described how statistical interpretation and Gutenberg -Richter relations are effective to understand the seismic pattern of the earthquake and aftershock behavior on the basis of earthquake data. The results indicated that there had been a notable number of events of the aftershock experienced in Nepal after main shock of $25^{\text {th }}$ April 2015. The calculated ' $b$ ' value from Gutenberg Richter law is an important parameter because it tells us proportionately how many large and small events are there [17]. The depth of earthquake occurrence shows that there is a shallow tremor because most of the earthquake was observed in $10 \mathrm{~km}$ depth. In Dolakha, Sindhupalchowk, Nuwakot, Gorkha, Dhading, and Rasuwa districts, more number of earthquakes was observed in 2015. The finding demonstrates that there is decreasing trend of aftershock with low intensity of magnitude event as days passes but due to the shallow tremor and unpredictable pattern of the earthquake there is a need of detail study to comprehend the seismic pattern of the earthquake. Nepal lies on the plate margin of Eurasian plate and Indian plate and hence there is higher chance of getting earthquakes in this region. Therefore, the government and policy makers should take this issue seriously and forward effective planning for minimizing casualties and disaster.

\section{REFERENCES}

[1] W. Stefan, "Earthquake statistics and earthquake prediction research,” ETH Honggerberg Zurich, 2003, pp. 1-11.

[2] V.J. David, B.Z. Yehuda, and Z. Ramon, Statistical Seismology, Vol. 162. Birkhauser Verlag: Switzerland, 2005.

[3] G. M. Molchan, and O.E. Dmitrieva, "Aftershock identification: methods and new approaches," Geophysical Journal International, ” June 1992, vol. 109, issue 3, pp 501-516, https://doi.org/10.1111/j.1365-246X.1992.tb00113.x

[4] USGS, “ Earthquake bulletins and catalog,” US Geological Survey National Earthquake Information Center, 2015, retrieved from http://earthquake.usgs.gov.

[5] A. Helmstetter, and D. Sornette, "Bath's law derived from the Gutenberg-Richter law and from aftershock properties," Journal of Geophysics, 2003.

[6] M. Tanvi, "The Nepal earthquake moved the whole city of Kathmandu ten feet," 2015, City Lab, retrieved from www.citylab.com

[7] USGS, “ USGS numerical aftershock analysis for the magnitude 7.8 Gorkha earthquake in Nepal April 25 ${ }^{\text {th }} 2015$," Technical Appendix, 2015, retrieved from http://earthquake.usgs.gov/earthquakes.

[8] S. Robert, L. T. Donald, and B. R. John, “Aftershock statistics," Pure and Applied Geophysics, 2005, vol, 162, issue 6-7, pp. 1051-1076, doi:10.1007/s00024-004-2661-8

[9] B. Gutenberg, and Ch. F. Richter, "Frequency of earthquakes in California," Bulletin of the Seismological Society of America, 1944, Vol. 34(4), pp. 185-188.

[10] S. Noora, "Estimating the probability of earthquake occurrence, and return period using generalized linear models," Journal of Geoscience and Environment Protection, 2019, Vol. 7, pp.11-24, doi: 10.4236/gep.2019.79002.

[11] A.G. Popandopoulos, and E. Chatziioannou, "Gutenberg-Richter law parameters analysis using the Hellenic unified seismic network data through fast bee technique," Earth Sciences, 2014, vol. 3 (5), pp.122-131, doi: 10.11648/j.earth.20140305.12.

[12] I. Main, "Statistical physics, seismogenesis, and seismic hazard," Reviews of Geophysics, Vol. 34(4), pp. 433-462.

[13] NEMRC, "Past Earthquakes," National Seismological Center, Department of Mines and Geology Nepal, 2015, retrieved from www.seismonepal.gov.np.

[14] A.G. Popandopoulos, and A. Lukk, "The depth variation in the b-value of frequency-magnitude distribution of the earthquakes in the gram region of Tajikistan, Izvestiya," Physics of the Solid Earth, 2014, vol. 50(2), pp. 273-288.

[15] C. Smyth, and J, Mori, "Temporal variations of the Gutenberg-Richter distribution prior to the Kobe earthquake," Annuals of Disaster, 2009, Vol. 52B, pp. 255-261. 
[16] F. Omori, “On the aftershocks of earthquakes," Journal of the college of Science, Imperial University of Tokyo, 1894, vol. 7, pp.111-120.

[17] M. Warner, and S. Laura, "A review and new insights on the estimation of the b-value and its uncertainty," Annals of Geophysics, 2003, vol. 46(6). pp. 1271-1282. 